\title{
Three-Year Results from the Venovo Venous Stent Study for the Treatment of Iliac and Femoral Vein Obstruction
}

\author{
Michael D. Dake ${ }^{1} \cdot$ Gerard O'Sullivan $^{2} \cdot$ Nicolas W. Shammas $^{3} \cdot$ Michael Lichtenberg $^{4}$ • \\ Bibombe P. Mwipatayi ${ }^{5} \cdot$ Richard A. Settlage $^{6}$ - for the VERNACULAR Trial \\ Investigators
}

Received: 19 August 2021/Accepted: 11 September 2021/Published online: 20 September 2021

(C) The Author(s) 2021

\begin{abstract}
Purpose To assess safety and patency of the Venovo venous stent for the treatment of iliofemoral vein obstruction.

Materials and Methods Twenty-two international centers enrolled 170 patients in the VERNACULAR study (93 post-thrombotic syndrome; 77 non-thrombotic iliac vein lesions). Primary outcome measures were major adverse events at 30 days and 12-month primary patency (freedom from target vessel revascularization, thrombotic occlusion, or stenosis $>50 \%$ ). Secondary outcomes included the
\end{abstract}

Michael D. Dake

mddake@arizona.edu

Gerard O'Sullivan

gerard.osullivan2@hse.ie

Nicolas W. Shammas

shammas@mchsi.com

Michael Lichtenberg

klichte@gmx.net

Bibombe P. Mwipatayi

patrice@bibombe.com

Richard A. Settlage

rasettlage@msn.com

1 University of Arizona Health Sciences, Health Sciences Innovation Building, 9Th Floor SVP Suite,1670 E. Drachman Street, P.O. Box 210216, Tucson, AZ 85721-0216, USA

2 University Hospital Galway, Galway, Ireland

3 Midwest Cardiovascular Research Foundation, Davenport, IA, USA

4 Arnsberg Vascular Clinic, Arnsberg, Germany

5 University of Western Australia Royal Perth Hospital, Perth, Australia

6 Becton Dickinson Peripheral Interventions, Tempe, AZ, USA
Venous Clinical Severity Score Pain Assessment and Chronic Venous Quality-of-Life Questionnaire assessments (hypothesis tested). Secondary observations included primary patency, target vessel and lesion revascularization (TVR/TLR), and assessment of stent integrity through 36 months.

Results Freedom from major adverse events through 30 days was $93.5 \%$, statistically higher than a pre-specified performance goal of $89 \%(p=0.032)$ while primary patency at 12 months was $88.6 \%$, also statistically higher than a performance goal of $74 \%(p<0.0001)$. Mean quality-of-life measures were statistically improved compared to baseline values at 12 months $(p<0.0001)$. Primary patency at 36 months was $84 \%$ (Kaplan-Meier analysis) while freedom from TVR/TLR was $88.1 \%$. There was no stent embolization/migration, and no core laboratory assessed stent fractures reported through 36 months. Six deaths were reported; none adjudicated as device or procedure related.

Conclusion The Venovo venous stent was successfully deployed in obstructive iliofemoral vein lesions and met the pre-specified primary outcome measures through 12 months. At 3 years, primary patency was $84 \%$, reintervention rates were low, standardized quality-of-life and pain measures improved from baseline, and there was no stent migration or fractures.

Level of Evidence Level 2-prospective, multicenter, controlled clinical study without a concurrent control or randomization. Pre-specified endpoints were hypothesistested to performance goals derived from peer-reviewed clinical literature.

Registration clinicaltrials.gov Unique Identifier NCT02655887. 
Keywords Iliofemoral venous obstruction - Iliac and femoral vein occlusive disease - Percutaneous endovenous stent $\cdot$ Post-thrombotic syndrome $\cdot$ Nonthrombotic iliac vein lesion

\section{Introduction}

Iliofemoral venous obstruction, caused by anatomic vein compression or deep vein thrombosis (DVT), can lead to severe venous insufficiency and a reduction in quality-oflife. Exercise, compression therapy, anticoagulation with thrombolysis, catheter-directed thrombolysis, or pharmacomechanical thrombectomy do not address the underlying causes of venous obstruction and have provided mixed therapeutic results [1-3]. Surgery has been used to bypass occlusions, but stent use has largely replaced surgery as the interventional procedure of choice [4]. Bare metal stents designed for arterial use have been used to treat peripheral venous obstructions, yet few have been systematically studied in the venous system [5-7]. Dedicated venous stents for iliofemoral venous outflow obstruction have emerged over the past few years as alternatives to conservative therapy, surgery, and the use of arterial stents. Observational single-center studies using the Venovo venous stent have reported good early patency and low complication rates [8-10]. The current prospective, multicenter study was designed and powered to evaluate major adverse events and primary patency of this dedicated, nitinol self-expanding, open-cell venous stent for iliofemoral obstructions through 12 months with secondary observations through 3 years.

\section{Methods and Materials}

\section{Study Design}

VERNACULAR was a prospective, multicenter study of the Venovo venous stent used to treat iliac and femoral vein thrombotic obstruction or venous compression. Between June 2016 and May 2017, 170 patients were treated at 22 centers in the USA, Europe, and Australia. Investigators followed a protocol approved by their institutional review board or ethics committee, patients provided written informed consent to participate in the study, and study procedures were conducted in accordance with the Declaration of Helsinki, good clinical practice, and other applicable healthcare regulations and privacy laws. A clinical events committee (CEC) provided independent oversight of patient safety, and a medical monitor reviewed adverse event trends. The Yale Cardiovascular Research Group (New Haven, CT) independently analyzed X-rays and venographic images while VasCore, the Vascular Ultrasound Core Laboratory (Massachusetts General Hospital, Boston, MA), reviewed duplex-ultrasound (DUS) images. VERNACULAR was sponsored by Bard/Becton, Dickinson and registered on clinicaltrials.gov (Unique Identifier: NCT02655887) prior to patient enrollment.

Eligible patients had symptomatic, non-malignant venous outflow obstruction in the iliac or femoral veins ( $\geq 50 \%$ by contrast venography) with a clinical-etiologicanatomic-pathophysiologic clinical score (CEAP "C" score) $\geq 3$ or a venous clinical severity score (VCSS) pain component $\geq 2$. Exclusion criteria included venous obstruction that extended into the inferior vena cava or below the level of the lesser trochanter, prior stent placement in the target vessel, or an iliac or femoral vein unsuitable for treatment with available device sizes.

\section{Outcome Measures}

The primary outcome measures included freedom from major adverse events (MAEs) through 30 days and 12-month primary patency, both compared to performance goals (PGs) derived from published clinical literature. MAEs included target vessel revascularization (TVR), device- or procedure-related DVT, target-limb major amputation, symptomatic pulmonary embolism, vascular injury requiring intervention, device migration, or death. Primary patency was defined as freedom from TVR, thrombotic occlusion, or stenosis greater than $50 \%$ measured by DUS and reviewed by the core laboratory. Secondary outcomes included quality-of-life (QoL) measures evaluated with the pain component of the VCSS and the Chronic Venous Quality-of-Life Questionnaire (CIVIQ-20 Global Index). QoL assessments were hypothesis-tested at 12 months to mean baseline values. Additional secondary observations included technical success, defined as successful deployment of the stent to the intended location with adequate lesion coverage and procedural success, technical success with no major adverse events between index procedure and discharge. Primary patency, TVR and target lesion revascularization (TLR; both core laboratory evaluated), CEAP classification scores, and stent integrity (i.e., migration and fracture) were reported through 3 years.

\section{Baseline Patient and Lesion Characteristics}

The treated population consisted of 170 patients who consented to participate in the study and received a stent (Fig. 1) and included 93 patients with post-thrombotic syndrome (PTS) and 77 patients with symptomatic non- 
Fig. 1 Summary of the final disposition of patients in the VERNACULAR Study. Two hundred thirty-one patients were enrolled, and 170 were treated with the Venovo venous stent. One hundred twenty-eight patients completed the study while 42 patients either withdrew consent or were withdrawn by an investigator (14), were lost to follow-up (19), died (6), or discontinued participation for other reasons (3). Due to the COVID-19 pandemic, the final 36-month follow-up window was extended beyond 1125 days to allow patients to complete the study

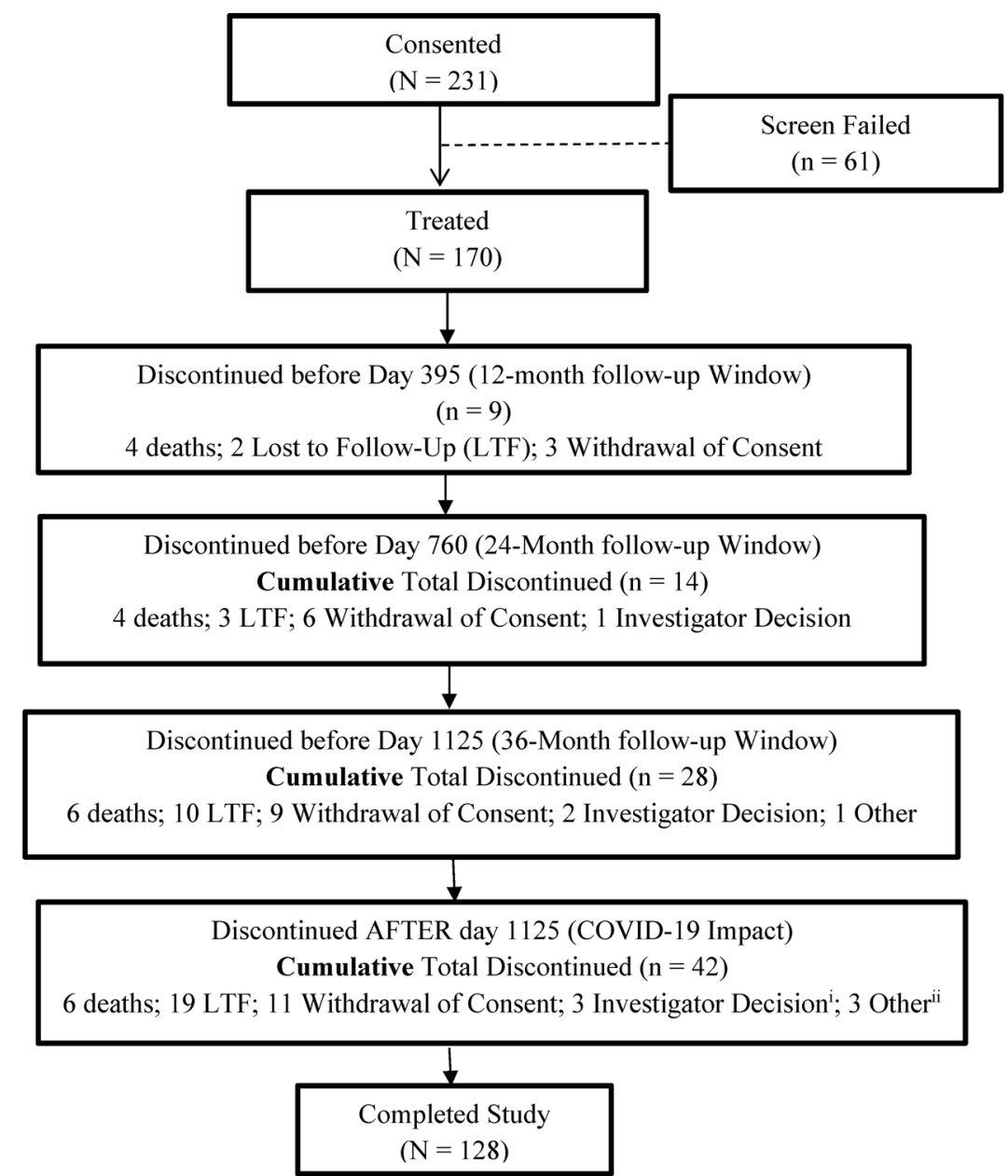

\footnotetext{
${ }^{\mathrm{i}}$ One patient had a stroke and could not return for follow up and two patients were non-compliant with the study and refused to return for follow up

ii Three patients refused to return for follow up (i.e., personal, transportation, and COVID-19 issues)
}

thrombotic iliac vein lesions (NIVL). Baseline patient demographics and medical histories are summarized in Table 1. At baseline, 235 lesions were evaluated by the venographic core laboratory. Patients could present with more than one lesion in multiple veins; $94.5 \%$ of patients had lesions in the common iliac vein, $40.5 \%$ in the external iliac vein, and $9.2 \%$ in the common femoral vein. The mean total lesion length per treated limb was $67.8 \pm 39.7 \mathrm{~mm}$, and the mean pre-procedure percent diameter stenosis was $75.7 \pm 17.0 \%$ (Table 2).

\section{Study Procedures and Follow-Up}

A comprehensive clinical history, physical examination, QoL assessment, and diagnostic venogram were performed prior to treatment to confirm study eligibility. Patients received prophylactic low-molecular-weight heparin prior to the procedure, 3000-5000 Units of unfractionated heparin during the procedure, and appropriate antiplatelet or anticoagulation medications post-procedure (e.g., acetylsalicylic acid, clopidogrel, rivaroxaban, apixaban) based on physician and institution standard-of-care guidelines. The Venovo venous stent (Bard/Becton, Dickinson and Company, Tempe, Arizona, USA) was used according to the device instructions for use. Stent diameters ranged from 10 to $20 \mathrm{~mm}$ ( $2 \mathrm{~mm}$ increments) and lengths from 40 to $160 \mathrm{~mm}$ (20 mm increments), the stent ends were flared approximately $3 \mathrm{~mm}$ larger than nominal stent diameter to provide fixation and prevent migration, and three radiopaque tantalum markers on each end of the stent enhanced 
Table 1 Baseline patient demographics, medical history, and additional procedures

\begin{tabular}{|c|c|c|c|}
\hline Patient demographics & PTS subgroup $N=93$ & NIVL subgroup $N=77$ & All treated $N=170$ \\
\hline Age (years), $\mathrm{X} \pm \mathrm{SD}$ & $49.8 \pm 15.0$ & $55.0 \pm 15.4$ & $52.1 \pm 15.3$ \\
\hline Male/Female, \% / \% & $45.2 / 54.8$ & $27.3 / 72.7$ & $37.1 / 62.9$ \\
\hline BMI, $\mathrm{kg} / \mathrm{m}^{2} \pm \mathrm{SD}$ & $28.6 \pm 6.4$ & $29.1 \pm 7.7$ & $28.8 \pm 7.0$ \\
\hline \multicolumn{4}{|l|}{ Race, \% (n) } \\
\hline Caucasian & $89.2(83)$ & $94.8(73)$ & $91.8(156)$ \\
\hline African American & $7.7(7)$ & $2.6(2)$ & $5.3(9)$ \\
\hline Asian & $3.2(3)$ & $1.3(1)$ & $2.4(4)$ \\
\hline \multicolumn{4}{|l|}{ Medical history, \% ( $n)$} \\
\hline Varicose Veins & $76.3(71)$ & $80.5(2)$ & $78.2(133)$ \\
\hline May-Thurner Syndrome & $37.6(35)$ & $87.0(67)$ & $60.0(102)$ \\
\hline Deep Vein Thrombosis & $98.9(92)$ & $0(0)$ & $54.1(92)$ \\
\hline Cigarette Smoking & $30.1(28)$ & $39.0(30)$ & $34.1(58)$ \\
\hline Hypertension & $29.0(27)$ & $36.4(28)$ & $32.4(55)$ \\
\hline Dyslipidemia & $21.5(20)$ & $35.1(27)$ & $27.6(47)$ \\
\hline Respiratory Disorder & $14.0(13)$ & $9.1(7)$ & $11.8(20)$ \\
\hline Diabetes & $5.4(5)$ & $16.9(13)$ & $10.6(18)$ \\
\hline Peripheral Arterial Disease & $6.5(6)$ & $15.6(12)$ & $10.6(18)$ \\
\hline Gastrointestinal Disease & $11.8(11)$ & $9.1(7)$ & $10.6(18)$ \\
\hline Coronary Artery Disease & $6.5(6)$ & $11.7(9)$ & $8.8(15)$ \\
\hline Coronary Intervention & $6.5(6)$ & $10.4(8)$ & $8.2(14)$ \\
\hline Venous Valve Disease & $7.5(7)$ & $6.5(5)$ & $7.1(12)$ \\
\hline Inferior Vena Cava Filter & $10.8(10)$ & $0(0)$ & $5.9(10)$ \\
\hline \multicolumn{4}{|l|}{ Additional procedures ${ }^{1}, \%(n)$} \\
\hline Previous Procedure ${ }^{2}$ & $20.4(19)$ & $13.0(10)$ & $17.1(29)$ \\
\hline 30-Day Planned Procedure ${ }^{3}$ & $9.7(9)$ & $2.6(2)$ & $6.5(11)$ \\
\hline
\end{tabular}

${ }^{1}$ Some patients had multiple procedures

${ }^{2}$ Procedure within 1 year of the study; most peripheral vascular interventions were for vena cava filter placement $(33 \%)$, thrombectomy (16\%), or venous procedures (e.g., venoplasty, ablation, or lysis)

${ }^{3}$ Planned peripheral endovascular or surgical intervention 30 days before or after the study procedure visibility to aid in placement. Stents were introduced through an 8-10 F sheath depending on device size. Up to two stents per patient were allowed per protocol with a recommended overlap of $10 \mathrm{~mm}$. Venograms were completed pre-deployment, at stent deployment, and at procedure completion and were sent to the venographic core laboratory for analysis. Follow-up visits at 1, 6, 12, 24, and 36 months included physical examination, target-limb assessment, documentation of reintervention or adverse events, assessment of changes in QoL, and DUS imaging. Anterior-posterior (A-P) radiographs were taken at 12, 24, and 36 months to evaluate possible stent fractures (analyzed by the Yale Core Laboratory).

\section{Statistical Analysis}

The treated sample size of 170 patients provided an overall power of $>85 \%$ for the pre-specified outcome measures. Freedom from MAEs was achieved if the one-sided $\mathrm{p}$ value was less than 0.05 or the lower limit of the two-sided $90 \%$ confidence limit was greater than a literature-derived PG of $89 \%$ (exact binomial method). MAEs reported in 19 peerreviewed articles ( $>2400$ patients) were used to derive a mean overall freedom from MAEs of 99\% [11-29]. The PG was set at a $10 \%$ non-inferiority margin below the literature-derived value at 30 days. Similarly, primary patency was achieved if the one-sided $\mathrm{p}$ value was less than 0.05 or the lower limit of the two-sided $90 \%$ confidence limit was greater than a PG of 74\% (weighted Z-statistics). The patency PG was derived from published data on stent treatment of lower-limb venous obstructions; primary patency data from fifteen NIVL studies (1149 limbs) $[11,13,15,23,25,27,28,30-37]$ and fourteen PTS studies (908 limbs) [11, 12, 14, 19-22, 24, 26, 28, 29, 38-40] were weighted and used to derive an overall mean primary patency rate (84\%); the PG was set at a $10 \%$ non-inferiority margin below the weighted literature-derived mean at 12 months. The VCSS pain score and CIVIQ-20 assessment at 12 months were hypothesis-tested to baseline values (Hochberg method for controlling multiple comparisons); 
Table 2 Baseline lesion characteristics and stent details

\begin{tabular}{|c|c|c|c|}
\hline Lesion characteristics $^{1}$ & PTS subgroup $N=89$ & NIVL subgroup $N=74$ & All treated $N=163^{2}$ \\
\hline \multicolumn{4}{|l|}{ Lesion Location ${ }^{3}, \%(n / N)$} \\
\hline Common Iliac Vein & $92.1(82 / 89)$ & $10.8(8 / 74)$ & $94.5(154 / 163)$ \\
\hline External Iliac Vein & $58.4(52 / 89)$ & $18.9(14 / 74)$ & $40.5(66 / 163)$ \\
\hline Common Femoral Vein & $14.6(13 / 89)$ & $2.7(2 / 74)$ & $9.2(15 / 163)$ \\
\hline Lesion Length, $\mathrm{mm}, \mu \pm \mathrm{SD}$ & $80.5 \pm 42.8$ & $55.2 \pm 32.0$ & $67.8 \pm 39.7$ \\
\hline Length Range, mm & $18.1-199.7$ & $22.3-183.4$ & $18.1-199.7$ \\
\hline Vessel Diameter, mm, $\mu \pm \mathrm{SD}$ & $16.0 \pm 2.7$ & $17.4 \pm 3.3$ & $16.7 \pm 3.0$ \\
\hline \multicolumn{4}{|l|}{ Diameter Stenosis, $\% \pm S D$} \\
\hline Baseline & $81.0 \pm 18.4$ & $69.3 \pm 12.6$ & $75.7 \pm 17.0$ \\
\hline After Pre-dilation & $49.9 \pm 21.1$ & $40.6 \pm 28.2$ & $47.8 \pm 22.9$ \\
\hline Final & $16.1 \pm 7.0$ & $12.1 \pm 5.3$ & $14.3 \pm 6.5$ \\
\hline \multicolumn{4}{|l|}{ Stent Details ${ }^{4}$} \\
\hline Diameter, mm, $\mu \pm \mathrm{SD}$ & $15.4 \pm 2.1$ & $16.6+2.0$ & $15.9 \pm 2.1$ \\
\hline Length, $\mathrm{mm}, \mu+\mathrm{SD}$ & $100.1 \pm 33.2$ & $83.0 \pm 26.3$ & $93.5 \pm 31.7$ \\
\hline Stents Placed, N & 134 & 85 & 219 \\
\hline Single Stent, \% (n) & $69.4(93)$ & $90.6(77)$ & $77.6(170)$ \\
\hline Distal Overlap, \% (n) & $20.1(27)$ & $4.7(4)$ & $14.2(31)$ \\
\hline Proximal Overlap, \% (n) & $10.4(14)$ & $4.7(4)$ & $8.2(18)$ \\
\hline Pre-dilation, \% (n) & $87.1(81)$ & $66.2(51)$ & $77.6(132)$ \\
\hline Post-dilation, \% (n) & $92.5(86)$ & $88.3(68)$ & $90.6(154)$ \\
\hline Technical Success, $\%(\mathrm{n} / \mathrm{N})$ & $100(93 / 93)$ & $100(77 / 77)$ & $100(170 / 170)$ \\
\hline Procedural Success, $\%(\mathrm{n} / \mathrm{N})$ & $97.8(91 / 93)$ & $100(77 / 77)$ & $98.8(168 / 170)^{5}$ \\
\hline
\end{tabular}

the reduction in pain and discomfort was deemed statistically significant if the two-sided $\mathrm{p}$ value (paired $t$ test) was less than 0.05 .

Additional secondary outcomes were reported using Kaplan-Meier (K-M) estimates and descriptive statistics through 3 years. Descriptive statistics included categorical variables presented as percentages and frequency counts, and continuous variables that included means \pm standard deviation (SD) and confidence intervals (CIs). Secondary outcomes beyond the hypothesis-tested measures at 12 months were observational.

\section{Results}

Two hundred nineteen (219) stents were used in 170 patients; one device was used in $77.6 \%$ of cases (Table 2). The mean stent length was $93.5 \pm 31.7 \mathrm{~mm}$ (range $40-160 \mathrm{~mm})$, and the mean stent diameter was $15.9 \pm 2.1 \mathrm{~mm}$ (range 10-20 mm). Technical success was achieved in all cases $(100 \%)$ while procedural success was
98.8\% (168/170); two PTS patients experienced a TVR for stent thrombosis prior to discharge. The final mean percent diameter stenosis after stent placement was $14.3 \pm 6.5 \%$.

\section{Post-procedure Follow-up and Outcomes}

One hundred twenty-eight patients completed the study at 3 years (Fig. 1). Primary and secondary outcome measures are summarized in Table 3. Freedom from MAEs at 30 days was $93.5 \%$ [90\% CI: $89.5 \%, 96.3 \%$ ], statistically higher than the literature-derived PG of $89 \%$ (one-sided exact binomial test; $p$ value $=0.03$ ). Analysis of patient subgroups demonstrated a numerical difference, but not a statistically significant difference in MAEs between the PTS subgroup (88.2\%) and the NIVL subgroup (100\%; $p=0.94$ logistic regression with subgroup as fixed effect). Twelve-month primary patency was 88.6\% [90\% CI: $82.8 \%, 94.4 \%$ ], also statistically higher than the literaturederived PG of $74 \%$ (one-sided exact binomial test; $p$ value $<0.0001)$. This was a weighted mean based on the distribution between the mean primary patency for the PTS 
Table 3 Primary results, hypothesis-tested secondary outcomes, and secondary observations

\begin{tabular}{|c|c|c|c|c|}
\hline Primary outcome measures & $\begin{array}{l}\text { PTS subgroup } \\
N=93\end{array}$ & $\begin{array}{l}\text { NIVL subgroup } \\
N=77\end{array}$ & $\begin{array}{l}\text { All treated } \\
N=170\end{array}$ & $\begin{array}{l}p \text { value } \\
{[90 \% \mathrm{CI}]}\end{array}$ \\
\hline Primary Patency ${ }^{1}, \%(\mathrm{n} / / \mathrm{N})$ & $81.7(67 / 82)$ & $97.1(66 / 68)$ & $88.6^{2}$ & $\begin{array}{c}<0.0001^{3} \\
{[82.8,94.4]}\end{array}$ \\
\hline $\begin{array}{l}\text { Freedom from MAEs }{ }^{4}, \% \\
\quad(\mathrm{n} / \mathrm{N})\end{array}$ & $88.2(82 / 93)$ & $100(77 / 77)$ & 93.5 & $\begin{array}{l}0.032^{5} \\
{[89.5,96.3]}\end{array}$ \\
\hline $\begin{array}{l}\text { Secondary outcome measures } \\
\text { (hypothesis tested) }\end{array}$ & & & & $p$ value \\
\hline \multicolumn{5}{|l|}{ VCSS Pain Score ${ }^{6}$} \\
\hline Baseline & $\begin{array}{l}2.2^{7} \\
{[2.1,2.4]}\end{array}$ & $\begin{array}{l}2.3 \\
{[2.1,2.4]}\end{array}$ & $\begin{array}{l}2.3 \\
{[2.2,2.4]}\end{array}$ & \\
\hline 12 Months & $\begin{array}{l}0.7 \\
{[0.5,0.9]}\end{array}$ & $\begin{array}{l}0.5 \\
{[0.3,0.7]}\end{array}$ & $\begin{array}{l}0.6 \\
{[0.5,0.7]}\end{array}$ & \\
\hline Change from Baseline & $\begin{array}{l}-1.5 \\
{[-1.8,-1.3]}\end{array}$ & $\begin{array}{l}-1.8 \\
{[-2.0,-1.6]}\end{array}$ & $\begin{array}{l}-1.7 \\
{[-1.8,-1.5]}\end{array}$ & $<0.0001^{8}$ \\
\hline \multicolumn{5}{|l|}{ CIVIQ-20 Score ${ }^{9}$} \\
\hline Baseline & $\begin{array}{l}52.5^{10} \\
{[48.6,56.4]}\end{array}$ & $\begin{array}{l}45.7 \\
{[41.8,49.5]}\end{array}$ & $\begin{array}{l}49.3 \\
{[46.5,52.0]}\end{array}$ & \\
\hline 12 Months & $\begin{array}{l}34.0 \\
{[30.5,37.6]}\end{array}$ & $\begin{array}{l}33.1 \\
{[29.3,36.9]}\end{array}$ & $\begin{array}{l}33.6 \\
{[31.0,36.2]}\end{array}$ & \\
\hline Change from Baseline & $\begin{array}{l}-18.5 \\
{[-22.2,-14.7]}\end{array}$ & $\begin{array}{l}-12.6 \\
{[-16.5,-8.7]}\end{array}$ & $\begin{array}{l}-15.7 \\
{[-18.4,-13.0]}\end{array}$ & $<0.0001^{11}$ \\
\hline Secondary observations & & & & {$[95 \% \mathrm{CI}]$} \\
\hline \multicolumn{5}{|l|}{ CEAP Score, mean $\pm S D$} \\
\hline Baseline & $3.4 \pm 1.0$ & $3.5 \pm 0.8$ & $3.5 \pm 0.9$ & \\
\hline 36 Months & $2.1 \pm 1.6$ & $2.0 \pm 1.5$ & $2.1 \pm 1.6$ & \\
\hline Change from Baseline & $\begin{array}{l}-1.3 \\
{[-1.7,-1.0]}\end{array}$ & $\begin{array}{l}-1.5 \\
{[-1.9,-1.2]}\end{array}$ & $\begin{array}{l}-1.4^{12} \\
{[-1.7,-1.2]}\end{array}$ & \\
\hline \multicolumn{5}{|l|}{ Freedom from TVR/TLR } \\
\hline 12 Months, \% (n/N) & $87.6(78 / 89)$ & $98.6(73 / 74)$ & $92.6(151 / 163)$ & {$[87.5,96.1]$} \\
\hline 24 Months, \% (n/N) & $82.8(72 / 87)$ & $97.3(72 / 74)$ & $89.4(144 / 161)$ & {$[83.6,93.7]$} \\
\hline 36 Months, \% (n/N) & $80.5(66 / 82)$ & $97.1(67 / 69)$ & $88.1(133 / 151)$ & {$[81.8,92.8]$} \\
\hline Primary Patency ${ }^{13}, \%(\mathrm{n} / \mathrm{N})$ & & & & {$[90 \% \mathrm{CI}]$} \\
\hline 24 Months & $75.6(62 / 82)$ & $95.4(62 / 65)$ & $84.4(124 / 147)$ & {$[78.6,89.1]$} \\
\hline 36 Months & $70.0(49 / 70)$ & $93.6(44 / 47)$ & $79.5(93 / 117)$ & {$[72.4,85.4]$} \\
\hline Stent Migration ${ }^{14}, \%(\mathrm{n} / \mathrm{N})$ & $0(0 / 93)$ & $0(0 / 77)$ & $0(0 / 170)$ & \\
\hline \multicolumn{5}{|l|}{ Stent Fracture ${ }^{15}, \%(n / N)$} \\
\hline 12 Months & $0(0 / 72)$ & $0(0 / 65)$ & $0(0 / 137)^{16}$ & \\
\hline
\end{tabular}


Table 3 continued

Secondary observations

$[95 \% \mathrm{CI}]$

24 Months

$0(0 / 65)$

$0(0 / 63)$

$0(0 / 128)$

36 Months

$0(0 / 53)$

$0(0 / 45)$

$0(0 / 98)$

${ }^{1}$ Primary patency was defined as freedom from TVR, thrombotic occlusion, or stenosis greater than 50\% measured by duplex ultrasonography (DUS) and reviewed by the DUS core laboratory

${ }^{2}$ Weighted mean based on the patency rates of PTS and NIVL subgroups

${ }^{3} 90 \%$ CI and one-sided p value is from the weighted Z-statistics and the combined patency rate was tested against the performance goal (PG) $(74 \%)$

${ }^{4}$ MAEs included target vessel revascularization (TVR), device- or procedure-related deep vein thrombosis (DVT), target-limb major amputation, symptomatic pulmonary embolism, vascular injury requiring either surgical or endovascular intervention, device migration, or death

${ }^{5}$ The p value is computed compared with performance goal of $89 \%$. The $90 \%$ confidence interval is calculated using the exact binomial method

${ }^{6}$ Pain component of the venous clinical severity score (VCSS) hypothesis-tested against baseline values at 12 months

${ }^{7}$ Mean and $95 \% \mathrm{CI}$ are presented based on normal assumption

${ }^{8}$ The $\mathrm{p}$ value is calculated from a two-sided paired $t$ test

${ }^{9}$ The Chronic Venous Quality-of-Life Questionnaire (CIVIQ-20) score hypothesis-tested against baseline values at 12 months

${ }^{10}$ Mean and $95 \% \mathrm{CI}$ are presented based on normal assumption

${ }^{11}$ The $\mathrm{p}$ value is calculated from a two-sided paired $t$ test

${ }^{12}$ Mean and $95 \%$ CI are presented based on normal assumption

${ }^{13}$ Unweighted proportional values with $90 \%$ CI estimated by exact binomial method

${ }^{14} \mathrm{CEC}$ adjudicated stent embolism/migration through 3 years

${ }^{15}$ Based on AP and lateral X-rays for each evaluated stent analyzed by the core laboratory

${ }^{16}$ Number of stents that had images available and readable for review

and NIVL subgroups. Analysis of patient subgroups demonstrated a statistically higher primary patency rate for the NIVL subgroup (96.9\%) compared to the PTS subgroup $(81.3 \% ; p=0.01$; type III test by logistic regression with subgroup as fixed effect). The VCSS pain score and the CIVIQ-20 global index were secondary QoL endpoints hypothesis-tested at 12 months to baseline values. The mean improvement in the VCSS pain score was -1.7 [95\% CI: $-1.8,-1.5]$ at 12 months (two-sided paired $t$ test; $p<0.0001$; Fig. 2A) and the mean improvement in the CIVIQ-20 global index score was -15.7 [95\% CI: -18.4 , -13.0] (two-sided paired $t$ test: $p<0.0001$; Fig. 2B), representing statistically significant improvements in overall pain and patient comfort from baseline.

Supportive analyses and secondary observations without formal hypothesis testing were conducted through 3 years. The unweighted primary patency rate (binary analysis) was $79.5 \%$ [90\% CI 72.4\%, 85.4\%] while the $\mathrm{K}-\mathrm{M}$ estimate of primary patency, accounting for patients censored (e.g., lost to follow-up) in the binary analysis, was $84.0 \pm 3.0 \%$ (1125 days: Fig. 3). The mean improvement from baseline in the VCSS pain score was -1.8 [95\% CI: $-2.0,-1.7]$, CIVIQ-20 global index was -16.8 [95\% CI: -20.1 , -13.5], and CEAP "C" score was -1.4 [95\% CI: -1.7 , $-1.2]$. Freedom from TVR/TLR (binary) was $88.1 \%$. No stent embolization or migration was reported, and $\mathrm{A}-\mathrm{P}$ and lateral radiographs at 12,24 , and 36 months, reviewed by the X-ray core laboratory, revealed no stent fractures.

Six deaths were reported through 3 years. In three cases, the investigator listed a specific cause of death (i.e., one case of rectal cancer and two cases of myocardial infarction). In the remaining three cases, the specific cause of death was not listed; post-mortem summaries, however, indicated the apparent causes as recurrent cancer, complications of liver cirrhosis, and age-related natural causes. The CEC adjudicated that no deaths were related to the stent.

\section{Discussion}

Contemporary clinical practice has established stenting of iliofemoral venous obstruction as a durable therapy with relatively few complications. Stents have been used most often in acute cases with severe symptoms and in chronic DVT patients with symptoms of moderate to severe PTS; most were designed for arterial use, so the guidance was appropriately prudent and meant to discourage overuse of arterial stents in cases without evidence-based justification [41, 42]. Four self-expanding nitinol stents, specifically designed to meet the challenges of venous obstructive disease, have now been FDA-approved and address the long-held realizations that venous lesions are 

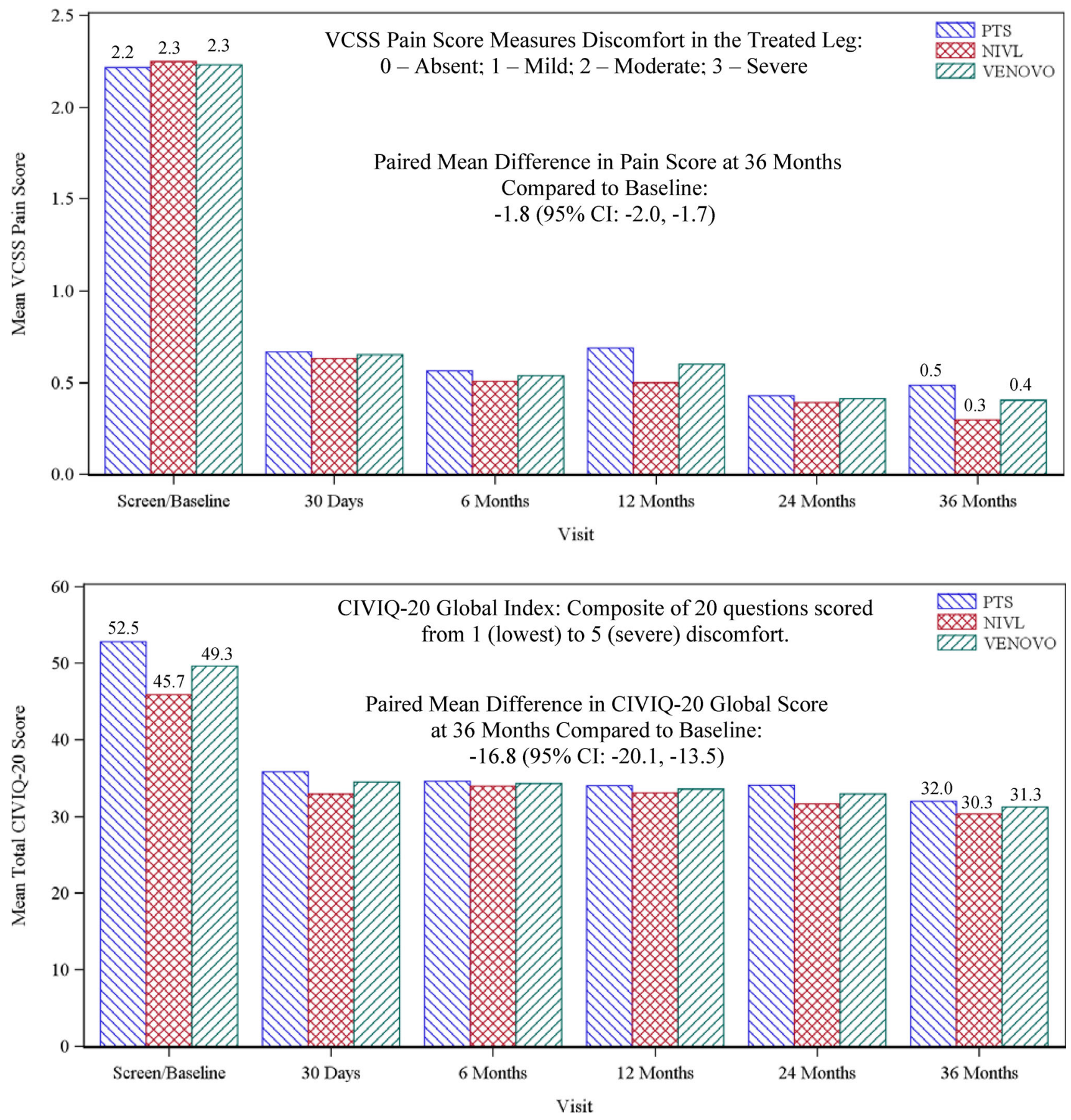

Fig. 2 Quality-of-life summary bar graphs through 36 months. The paired mean improvement in the VCSS pain score at 36 months was 1.8 [95\% CI: $-2.0,-1.7]$ and the paired mean improvement in

fundamentally different than the pathological disease that typically affects arteries; that vessel compliance, wall composition, and blood flow are distinctly dissimilar between arteries and veins; and that the basic dimensions (e.g., diameter, wall thickness) of iliac arteries and veins are disparate.
CIVIQ-20 global index score was -16.8 [95\% CI: $-20.1,-13.5]$ both compared to baseline values

One- and two-year data from the current trial and the three other venous-specific stent trials-VIRTUS (Vici Venous stent), VIVO (Zilver Vena), and ABRE (Abre venous stent) - have been presented or published [43-45]. The 3-year results of the VERNACULAR trial, however, are the longest-term follow-up data published on a venousspecific stent. Primary patency was superior to a literature- 


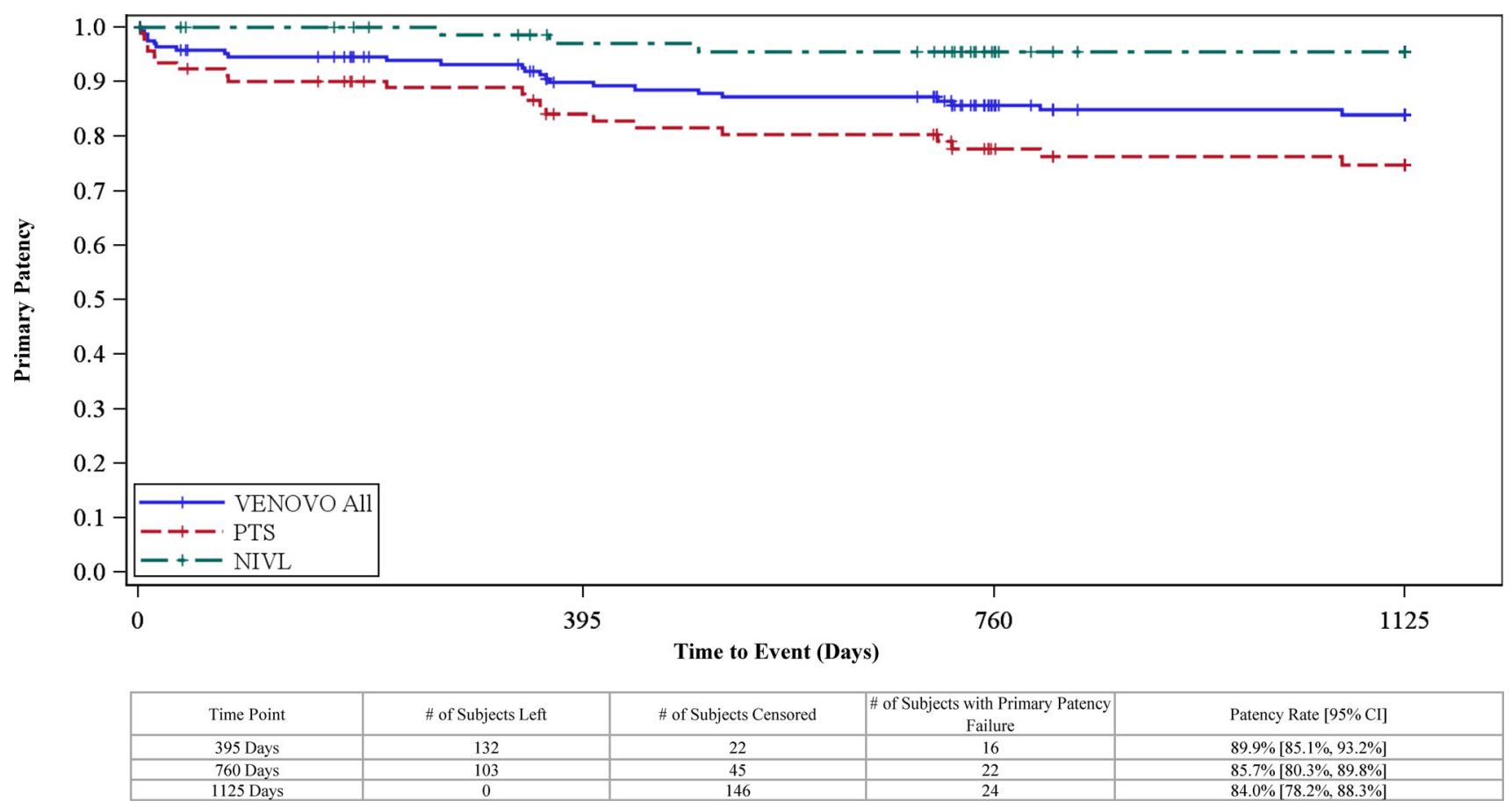

Fig. 3 Kaplan-Meier curve of primary patency through 3 years. The estimated primary patency rate at 1125 days, the end of the 3-year followup window, was $84.0 \%$ [95\% CI: $78.2 \%, 88.3 \%$ ]

based performance goal at 1 year $(p<0.0001)$ and was sustained at 3 years $(79.5 \%)$ with a relative drop in the patency rate of only 9\% from 1 to 3 years. The KaplanMeier estimate of primary patency was $84 \%$ while freedom from TVR and TLR was $88.1 \%$ at 3 years.

It is difficult to compare results between the venous stent trials because of differences in patient demographics, anatomic characteristics as well as specific differences in protocol-defined inclusion criteria and outcome measures. There are also differences in stent designs, open cell (Venovo, Zilver Vena, Abre) versus closed cell (Vici); the former typically providing greater device flexibility while closed-cell stents accentuate resistance to external compression [46]. The Venovo stent has some distinct features such as $3 \mathrm{~mm}$ flared stent ends designed for anchoring and the largest venous stent diameter range (10-20 mm). Given the mean diameter of treated veins in multiple trials was $>15 \mathrm{~mm}$, and $13 \%$ of patients in the VIRTUS trial were excluded because the vein diameter was $<12 \mathrm{~mm}$ or $>16 \mathrm{~mm}$, the large diameter range may prove useful [43].

Although not directly comparable, observations from the four trials can provide insight on the performance of venous stents. First, patient demographics across trials were similar, composed predominantly of women (range $63 \%$ to $70 \%$ ), with a mean age ranging from 51 to 54 years, and with lesions overwhelmingly affecting the left leg (up to 90\%). Total occlusions were present in $26 \%$ to $32 \%$ of cases with a baseline mean diameter vein stenosis of $63-78 \%$. Second, there appeared to be no clear differences in safety endpoints observed through 30 days between the studies based on similar composite metrics. Freedom from MAEs at 30 days in the VERNACULAR trial was $93.5 \%$, statistically higher compared to the safety performance goal. Third, primary patency rates were clustered from 84 to $90 \%$ at 1 year. Patency outcomes for the NIVL subgroups ranged from 96 to $99 \%$, and as anticipated, the patency outcomes for the PTS subgroups were uniformly lower (VERNACULAR $81.7 \%$; VIRTUS 79.8\%, ABRE 79.8\%, and Vici Venous Stent Trial 59\%). At 3 years, the primary patency rate for the VERNACULAR trial was $79.5 \%$ (93.6\% and 70\%, respectively, for the NIVL and PTS subgroups). Fourth, paralleling the patency outcomes, TVR-free rates through the first 24 months were consistent across the dedicated venous stent studies (e.g., VERNACULAR 89.4\%, VIRTUS $88.7 \%$ ) while the rate in the VERNACULAR trial remained consistent at 3 years $(88.1 \%)$. Fifth, there was no stent embolization or migration and no stent fractures observed in the VERNACULAR trial through 3 years; migration $(0-1 \%)$ and fractures $(0-4 \%)$ were also rare in the other trials at 1 and 2 years. Finally, lower VCSS scores and improved quality-of-life results (EQ-5D Index, Chronic Venous Quality-of-Life Questionnaire-CIVIQ-20 
Global Index) were observed through all follow-up time points compared to pre-intervention assessments. At 3 years in the VERNACULAR trial, the mean improvement from baseline in the VCSS pain score was -1.8 and in the CIVIQ-20 score was -16.8 . Similar QoL improvements were observed in the other dedicated venous stent trials at earlier time points, but clinical outcome studies comparing arterial stents and dedicated venous stents for management of iliofemoral venous disease have not been performed.

Limitations of the current trial included the single-arm design that used historical rather than concurrent, randomized controls. The trial was prospective, multicentered, and had pre-specified endpoints powered to detect differences compared to performance goals; there can be selection bias, however, in the choice of historical studies. The case mix, trial design, and study methodology may be different than the studies used to determine the PGs, and the use of other studies could have yielded different results. The study was not designed to assess clinical success compared to non-venous stents. It is also possible that the Venovo stent performed differently than venous stents used in other trials. A comparative, randomized study powered to determine differences between stents would be needed within the same demographic population. Forty-two patients discontinued prior to the end of the study resulting in an overall follow-up rate of $75.3 \%$. The COVID-19 pandemic impacted the final follow-up at 3 years, and an attrition of approximately $25 \%$ could have impacted the results. The primary outcome measures and secondary quality-of-life parameters at 12 months were statistically powered and hypothesis-tested, but additional secondary analyses out to 3 years were observational only.

Recent data from dedicated venous stent trials for iliac and femoral vein occlusive disease provide interventionalists with clear outcomes that can be anticipated through 1 year following stent placement. Three-year results from the VERNACULAR trial using the Venovo venous stent are the longest-term follow-up data from a controlled multicenter trial. Primary patency and stent integrity were sustained at 2 and 3 years, reintervention rates were low, and patient quality-of-life improved, providing physicians and patients with important predictability and confidence in the durability of the earlier outcomes.

Acknowledgements The authors thank Katie Retherford, Senior Manager, Clinical Sciences, Becton Dickinson Peripheral Interventions for her oversight and management of the VERNACULAR Study. The authors also wish to thank Alexandra Lansky, MD and Ecaterina Cristea, MD of the Yale Cardiovascular Research Group and Ido Weinberg, MD and Gail Hadley, RN of the Vascular Ultrasound Core Laboratory. Finally, the authors thank the following investigators who participated in the VERNACULAR trial: Professor Thomas Zeller, MD, Steven Black, MD, Michiel de Haan, MD, Rick de Graaf, MD, Professor Luis Miguel Izquierdo Lamoca, MD, Houman Jalaie, MD, Steven Dubenec, MD, Jeffrey Apple, MD, Robert
Lookstein, MD, John Mullins, MD, David Dexter, MD, Shadi AbuHalimah, MD, Brian Ferris, MD, Barbara Karenko, MD, Fadi Saab, MD, Robert Mendes, MD, Khanjan Nagarsheth, MD, Robert Attaran, MD, Ronald Morford, MD, and Paul Gagne, MD.

Funding VERNACULAR was a U.S. Food and Drug Administration (FDA) Investigational Device Exemption (IDE) Study supported by C. R. Bard, a wholly owned subsidiary of Becton, Dickinson and Company.

\section{Declarations}

Conflict of interest MDD is a member of the Scientific Advisory Board of W.L. Gore and consultant to Cook Medical. GO is a consultant and received speaker honoraria from Cook Medical, C. R. Bard (Bard)/Becton, Dickinson and Company (BD), Boston Scientific, Philips, Medtronic, WhiteSwell, VeinWay, and Vivasure as well as a shareholder in Marvao Medical. NWS has received research and educational grants from Bard/BD, Boston Scientific, Phillips, AngioDynamics, and VentureMed Group, is on the advisory board of VentureMed group and CSI, and has received speaker honoraria from Janssen, Boehringer Ingelheim, Lilly, Kiniksa, Amgen, and Esperion. ML has received research grants and speaker honoraria from Bard/ BD. BPM has received research and educational grants from Boston Scientific, Getinge, and Medtronic Australia as well as speaker honoraria from Bard/BD, Boston Scientific, Getinge, Gore, and Medtronic Australia. RAS is an employee and shareholder of Becton, Dickinson and Company.

Consent for publication Consent for publication was obtained as part of the written informed consent. All patients consented to publication of the study results if their identity remained confidential.

Ethical Approval All procedures performed on human participants were done in accordance with the ethical standards of the institutional and/or national research committee and with the 1964 Helsinki declaration and its later amendments or comparable ethical standards.

Informed Consent Informed consent was obtained from all individual participants included in the study.

Open Access This article is licensed under a Creative Commons Attribution 4.0 International License, which permits use, sharing, adaptation, distribution and reproduction in any medium or format, as long as you give appropriate credit to the original author(s) and the source, provide a link to the Creative Commons licence, and indicate if changes were made. The images or other third party material in this article are included in the article's Creative Commons licence, unless indicated otherwise in a credit line to the material. If material is not included in the article's Creative Commons licence and your intended use is not permitted by statutory regulation or exceeds the permitted use, you will need to obtain permission directly from the copyright holder. To view a copy of this licence, visit http://creativecommons. org/licenses/by/4.0/.

\section{References}

1. Enden T, Haig Y, Klow NE, Slagsvold CE, Sandvik L, Ghanima W, Hafsahl G, Holme PA, Holmen LO, Njaastad AM, Sandbaek G, Sandset PM, CaVenT Study Group. Long-term outcome after additional catheter-directed thrombolysis versus standard treatment for acute iliofemoral deep vein thrombosis (the CaVenT 
study): a randomized controlled trial. Lancet. 2012;379:31-8. https://doi.org/10.1016/S0140-6736(11)61753-4.

2. Haig Y, Enden T, Grotta O, Klow NE, Slagsvold CE, Ghanima W, Sandvik L, Hafsahl G, Holme PA, Holmen LO, Njaastad AM, Sandbaek G, Sandset PM, CaVenT Study Group. Post-thrombotic syndrome after catheter-directed thrombolysis for deep vein thrombosis (CaVenT): 5-year follow-up results of an open-label randomized controlled trial. Lancet Haematol. 2016;3:e64-71. https://doi.org/10.1016/S2352-3026(15)00248-3.

3. Vedantham S, Goldhaber SZ, Julian JA, Kahn SR, Jaff MR, Cohen DJ, Magnuson E, Razavi MK, Comerota AJ, Gornik HL, Murphy TP, Lewis L, Duncan JR, Nieters P, Derfler MC, Filion M, Gu CS, Kee S, Schnieder J, Saad N, Blander M, Moll S, Sacks D, Lin J, Rundback J, Garcia M, Razdan R, Vander-Woude E, Marques V, Kearon C, ATTRACT Trial Investigators. Pharmacomechanical catheter-directed thrombolysis for deep vein thrombosis. N Eng J Med. 2017;377:2240-52. https://doi.org/10. 1056/NEJMoa1615066.

4. Jost CJ, Gloviczki P, Cherry KJ Jr, McKusick MA, Harmsen WS, Jenkins GD, Bower TC. Surgical reconstruction of iliofemoral veins and the inferior vena cava for nonmalignant occlusive disease. J Vasc Surg. 2001;33:320-8. https://doi.org/10.1067/ mva.2001.112805.

5. Gutzeit A, Zollikofer CHL, Dettling-Pizzolato M, Graf N, Largiade' $r$ J, Binkert CA. Endovascular stent treatment for symptomatic benign iliofemoral venous occlusive disease: Long-term results 1987-2009. Cardiovasc Intervent Radiol. 2011;34:542-9. https://doi.org/10.1007/s00270-010-9927-6.

6. Ignatyev IM, Pokrovsky A, Gradusov E. Long-term results of endovascular treatment of chronic iliofemoral venous obstructive lesions. Vasc Endovascular Surg. 2019;53(5):373-8. https://doi. org/10.1177/1538574419839256.

7. Qiu P, Zha B, Xu A, Wang W, Zhan Y, Zhu X, Yuan X. Systematic review and meta-analysis of iliofemoral stenting for postthrombotic syndrome. Eur J Vasc Endovasc Surg. 2019;57:407-16. https://doi.org/10.1016/j.ejvs.2018.09.022.

8. Lichtenberg MKW, Stahlhoff WF, Stahlhoff S, Özkapi A, Rassaf T, Breuckmann F, de Graff R. Venovo venous stent in the treatment of non-thrombotic or post-thrombotic iliac vein lesions-long-term results from the Arnsberg venous registry. Vasa. 2020;50:52-8. https://doi.org/10.1024/0301-1526/a000893.

9. Shammas NW. Worsening back and lower leg pain post stenting of the common iliac vein: is there evidence it is related to stent size? J Invasive Cardiol. 2020;32(10):E250-3.

10. Tang TY, Lim MHH, Damodharan K, Yap CJQ, Lee SQW, Yap HY, Chong TT, Tan JWH. Use of the VENOVO ${ }^{\mathrm{TM}}$ and Sinus Obliquus ${ }^{\mathrm{TM}}$ venous stents in the treatment of non-thrombotic or post-thrombotic iliac vein lesions - Short-term results from a multi-centre Asian cohort. Phlebology. 2021;36(1):70-8. https:// doi.org/10.1177/0268355520946219.

11. Neglén P, Hollis KC, Olivier J, Raju S. Stenting of the venous outflow in chronic venous disease: long-term stent-related outcome, clinical, and hemodynamic result. J Vasc Surg. 2007;46:979-90. https://doi.org/10.1016/j.jvs.2007.06.046.

12. Kurlinsky AK, Bjarnason H, Friese JL, Wysokinski WE, McBane RD, Misselt A, Moller SM, Gloviczki P. Outcomes of venoplasty with stent placement for chronic thrombosis of the iliac and femoral veins: single-center experience. J Vasc Interv Radiol. 2012;23:1009-15. https://doi.org/10.1016/j.jvir.2012.04.019.

13. Meng Q-y, Li X-q, Qian A-m, Sang H-f, Rong J-j, Zhu L-w. Endovascular treatment of iliac vein compression syndrome. Chin Med J. 2011;124(20):3281-4. https://doi.org/10.3760/cma.j. issn.0366-6999.2011.20.013.

14. AbuRahma AF, Perkins SE, Wulu JT, Ng HK. Iliofemoral deep vein thrombosis: conventional therapy versus lysis and percutaneous transluminal angioplasty and stenting. Ann Surg.
2001;233:752-60. https://doi.org/10.1097/00000658-20010600000004.

15. Ye K, Lu X, Li W, Huang Y, Huang X, Lu M, Jiang M. Longterm outcomes of stent placement for symptomatic nonthrombotic iliac vein compression lesions in chronic venous disease. J Vasc Interv Radiol. 2012;23:497-502. https://doi.org/10.1016/j. jvir.2011.12.021.

16. O'Sullivan GJ, Sheehan J, Lohan D, McCann-Brown JA. Iliofemoral venous stenting extending into the femoral region: initial clinical experience with the purpose-designed Zilver Vena stent. J Cardiovasc Surg. 2013;54:255-61.

17. George R, Verma H, Ram B, Tripathi R. The effect of deep venous stenting on healing of lower limb venous ulcers. Eur J Vasc Endovasc Surg. 2014;48(3):330-6. https://doi.org/10.1016/ j.ejvs.2014.04.031.

18. Raju S, Tackett P Jr, Neglen P. Reinterventions for nonocclusive iliofemoral venous stent malfunctions. J Vasc Surg. 2009;49:511-8. https://doi.org/10.1016/j.jvs.2008.08.003.

19. Köbel T, Lindh M, Åkesson M, Wassèlius J, Gottsäter A, Ivancev $\mathrm{K}$. Chronic iliac vein occlusion: midterm results of endovascular recanalization. J Endovasc Ther. 2009;16:483-91. https://doi.org/ 10.1583/09-2719.1.

20. Rosales A, Sandbæck G, Jørgensen JJ. Stenting for chronic postthrombotic vena cava and iliofemoral venous occlusions: Midterm patency and clinical outcome. Eur J Vasc Endovasc Surg. 2010;40(2):234-40. https://doi.org/10.1016/j.ejvs.2010.04.016.

21. Wahlgren C-M, Wahlberg E, Olofsson P. Endovascular treatment in postthrombotic syndrome. Vasc Endovascular Surg. 2010;44(5):356-60. https://doi.org/10.1177/1538574410369710.

22. Alerany MB, Lamoca LMI, Ortega MR, Rivas IL, Desboeufs RZ, Kiuri SS. Endovascular treatment of iliofemoral chronic postthrombotic venous flow obstruction. J Vasc Surg Venous and Lym Dis. 2014;2:2-7. https://doi.org/10.1016/j.jvsv.2013.07.003.

23. Matsuda A, Yamada N, Ogihara Y, Tsuji A, Ota S, Ishikura K, Nakamura M, Ito M. Early and long-term outcomes of venous stent implantation for iliac venous stenosis after catheter-directed thrombolysis for acute deep vein thrombosis. Circ J. 2014;78:1234-9. https://doi.org/10.1253/circj.CJ-13-1247.

24. Hokimoto S, Saito T, Oshima S, Ogawa H. Initial and mid-term outcomes of pulse infusion thrombolysis using a unique pump system and stent placement for deep vein thrombosis. Inter Med. 2008;47:1663-7. https://doi.org/10.2169/internalmedicine.47. 1024.

25. Hurst DR, Forauer AR, Bloom JR, Greenfield LJ, Wakefield TW, Williams DM. Diagnosis and endovascular treatment of iliocaval compression syndrome. J Vasc Surg. 2001;34:106-13. https://doi. org/10.1067/mva.2001.114213.

26. Nazarian GK, Bjarnason H, Dietz CA Jr, Bernadas CA, Hunter DW. Iliofemoral venous stenoses: effectiveness of treatment with metallic endovascular stents. Radiology. 1996;200(1):193-9. https://doi.org/10.1148/radiology.200.1.8657909.

27. Park JY, Ahn JH, Jeon YS, Cho SG, Kim JY, Hong KC. Iliac vein stenting as a durable option for residual stenosis after catheterdirected thrombolysis and angioplasty of iliofemoral deep vein thrombosis secondary to May-Thurner syndrome. Phlebology. 2013;29(7):461-70. https://doi.org/10.1177/0268355513491724.

28. Titus JM, Moise MA, Bena J, Lyden SP, Clair DG. Iliofemoral stenting for venous occlusive disease. J Vasc Surg. 2011;53:706-12. https://doi.org/10.1016/j.jvs.2010.09.011.

29. Ye K, Lu X, Jiang M, Yang X, Li W, Huang Y, Huang X, Lu M. Technical details and clinical outcomes of transpopliteal venous stent placement for postthrombotic chronic total occlusion of the iliofemoral vein. J Vasc Interv Radiol. 2014;25:925-32. https:// doi.org/10.1016/j.jvir.2014.02.031.

30. Jeon UB, Chung JW, Jae HJ, Kim H-C, Kim SJ, Ha J, Park JH. May-thurner syndrome complicated by acute iliofemoral vein 
thrombosis: helical CT venography for evaluation of long-term stent patency and changes in the iliac vein. AJR. 2010;195:751-7. https://doi.org/10.2214/AJR.09.2793.

31. Oguzkert L, Tercan F, Ozkan U, Gulcan O. Iliac vein compression syndrome: Outcome of endovascular treatment with longterm follow-up. Eur J Radiol. 2008;68:487-92. https://doi.org/10. 1016/j.ejrad.2007.08.019.

32. Binkert CA, Schoch E, Stuckmann G, Largiader J, Wigger P, Schoepke W, Zollikofer CL. Treatment of pelvic venous spur (may-thurner syndrome) with self-expanding metallic endoprostheses. Cardiovasc Intervent Radiol. 1998;21:22-6. https:// doi.org/10.1007/s002709900205.

33. Hartung O, Otero A, Boufi M, Decaridi G, Barthelemy P, Juhan C, Alimi YS. Mid-term results of endovascular treatment for symptomatic chronic nonmalignant iliocaval venous occlusive disease. J Vasc Surg. 2005;42:1138-44. https://doi.org/10.1016/j. jvs.2005.08.012.

34. Knipp BS, Ferguson E, Williams DM, Dasika NJ, Cwikiel W, Henke PK, Wakefield TW. Factors associated with outcome after interventional treatment of symptomatic iliac vein compression syndrome. J Vasc Surg. 2007;46:743-9. https://doi.org/10.1016/j. jvs.2007.05.048.

35. Kwak H-S, Han Y-M, Lee Y-S, Jin G-Y, Chung G-H. Stents in Common iliac vein obstruction with acute ipsilateral deep venous thrombosis: early and late results. J Vasc Interv Radiol. 2005;16:815-22. https://doi.org/10.1097/01.RVI.0000157690. 91690.38 .

36. O’Sullivan GJ, Semba CP, Bittner CA, Kee ST, Razavi MK, Sze DY, Dake MD. Endovascular management of iliac vein compression (may-thurner) syndrome. J Vasc Interv Radiol. 2000;11:823-36. https://doi.org/10.1016/s1051-0443(07)617965.

37. Zhu QH, Zhou CY, Chen Y, Wang J, Mo HY, Luo MH, Huang $\mathrm{W}, \mathrm{Yu}$ XF. Percutaneous manual aspiration thrombectomy followed by stenting for iliac vein compression syndrome with secondary acute isolated iliofemoral deep vein thrombosis: a prospective study of single-session endovascular protocol. Eur J Vasc Endovasc Surg. 2014;47:68-74. https://doi.org/10.1016/j. ejvs.2013.09.030

38. Sang H, Li X, Qian A, Meng Q. Outcome of endovascular treatment in postthrombotic syndrome. Ann Vasc Surg. 2014;28:1493-500. https://doi.org/10.1016/j.avsg.2014.03.031.

39. Bjarnason H, Kruse JR, Asinger DA, Nazarian GK, Dietz CA Jr, Caldwell MD, Key NS, Hirsch AT, Hunter DW. Iliofemoral deep venous thrombosis safety and efficacy outcome during 5 years of catheter-directed thrombolytic therapy. J Vasc Interv Radiol. 1997;8:405-18. https://doi.org/10.1016/s1051-0443(97)70581-5.

40. Warner CJ, Goodney PP, Wallaert JB, Nolan BW, Rzucidlo EM, Powell RJ, Walsh DB, Stone DH. Functional outcomes following catheter-based iliac vein stent placement. Vasc Endovascular Surg. 2013;47(5):331-4. https://doi.org/10.1177/ 1538574413487443.

41. Wittens C, Davies AH, Bækgaard N, Broholm R, Cavezzi A, Chastanet S, de Wolf M, Eggen C, Giannoukas A, Gohel M, Kakkos S, Lawson J, Noppeney T, Onida S, Pittaluga P, Thomis S, Toonder I, Vuylsteke M. Management of chronic venous disease: clinical practice guidelines of the European Society for Vascular Surgery (ESVS). Eur J Vasc Endovasc Surg. 2015;49:678-737. https://doi.org/10.1016/j.ejvs.2015.02.007.

42. Kahn SR, Comerota AJ, Cushman M, Evans NS, Ginsberg JS, Goldenberg NA, Gupta DK, Prandoni P, Vedantham S, Walsh E, Weitz JI, on behalf of the American Heart Association Council on Peripheral Vascular Disease, Council on Clinical Cardiology, and Council on Cardiovascular and Stroke Nursing. The postthrombotic syndrome: evidence-based prevention, diagnosis, and treatment strategies. Circulation. 2014;130:1636-61. https://doi. org/10.1161/CIR.0000000000000130.

43. Razavi MK, Black S, Gagne P, Chiacchierini R, Nicolini P, Marston W, VIRTUS Trial Investigators. Pivotal study of endovenous stent placement for symptomatic iliofemoral venous obstruction. Circ Cardiovasc Interv. 2019;12:e08268.

44. Razavi M, Marston W, Black S, Bentley D, Neglen P. The initial report on 1-year outcomes of the feasibility study of the VENITI VICI VENOUS Stent in symptomatic iliofemoral venous obstruction. J Vasc Surg Venous Lym Dis. 2018;6:192-200. https://doi.org/10.1016/j.jvsv.2017.10.014.

45. Black S, Gwozdz A, Karunanithy N, Silickas J, Breen K, Hunt B, Smith A, Cohen A, Saha P. Two year outcome after chronic iliac vein occlusion recanalization using the Vici Venous Stent. Eur J Vasc Endovasc Surg. 2018;56:710-8. https://doi.org/10.1016/j. ejvs.2018.07.014.

46. Dabir D, Feisst A, Thomas D, Luetkens JA, Meyer C, Kardulovic A, Menne M, Steinseifer U, Schild HH, Kuetting DLR. Physical properties of venous stents: an experimental comparison. Cardiovasc Intervent Radiol. 2018;41(6):942-50. https://doi.org/10. 1007/s00270-018-1916-1.

Publisher's Note Springer Nature remains neutral with regard to jurisdictional claims in published maps and institutional affiliations. 